\title{
Potential of aquaporins and connexins in dogs and their relation to the reproductive tract
}

\author{
MAGDALENA KULUS*, MARIA WIECZORKIEWICZ**, JAKUB KULUS***, \\ MARIUSZ T. SKOWROŃSKI ${ }^{* *}$, WIESŁAWA KRANC ${ }^{* * * *}$, DOROTA BUKOWSKA***, \\ GRZEGORZ WĄSIATYCZ*, BARTOSZ KEMPISTY*,****,*****,******, PAWEŁ ANTOSIK*
}

\author{
${ }^{*}$ Department of Veterinary Surgery, **Department of Basic and Preclinical Sciences, \\ ***Department of Diagnostics and Clinical Sciences, Institute of Veterinary Medicine, \\ Nicolaus Copernicus University in Toruń, 7 Gagarina St., 87-100 Toruń, Poland \\ ****Department of Anatomy, *****Department of Histology and Embryology, \\ Poznań University of Medical Sciences, 6 Święcickiego St., 60-781 Poznań, Poland \\ ******Department of Obstetrics and Gynecology, University Hospital and Masaryk University, \\ Obilní trh 526/11, 60200 Brno, Czech Republic
}

Kulus M., Wieczorkiewicz M., Kulus J., Skowroński M. T., Kranc W., Bukowska D., Wąsiatycz G., Kempisty B., Antosik P.

Potential of aquaporins and connexins in dogs and their relation to the reproductive tract

Summary

The complexity of processes in the female reproductive system of mammals is extremely sophisticated. The overall relationship between the processes during the oestrus cycle in animals is quite well understood, but the molecular background of these processes still requires an in-depth analysis. Bitches are distinguished by a specific course of sexual cycle during which the oocyte matures after ovulation in the oviduct. Other species of mammals are characterized by maturation of the oocyte within the ovary. Acquisition of developmental competence by cumulus - oocyte complexes seems to be a process with a complex molecular background, and the key to understanding it may be the analysis of intercellular channels. Aquaporins and connexins are structural proteins that are built into the cell membrane. Their location is widespread in many body tissues. Recent years have shown that they exhibit significant expression in different parts of the mammalian reproductive system, although the number of studies on dogs is still negligible. This review paper presents the current state of knowledge of water channels and gap junction connections in different animal species, with particular focus on dogs, and also explores the role of aquaporins and connexins in the acquisition of reproductive competences.

Keywords: aquaporins, connexins, reproduction, canine

The processes taking place in the broadly defined female reproductive system, including ovaries, fallopian tubes, uterus and external reproductive organs, are highly complex. Mutual cellular relations, transmission of signals directly and also through blood have not been fully understood. An in-depth analysis of the molecular basis of processes at the level of cells and their membranes seems to be the key to further understanding of mammalian reproductive system physiology.

The study on developmental competence acquisition by oocytes and surrounding cells is still a current problem for scientists (34). The domestic canine species differ significantly in regard to ovulation and competence acquisition by cumulus oocyte complexes (COCs) from other domestic animal species $(10,14)$.

In the vast majority of mammalian species, the oocyte matures within the ovarian follicle and is retained at the moment of ovulation in metaphasis II (MII) of meiotic division (55). First, in bitches, the oocyte matures in the follicle to the prophase I stage of meiosis and further maturation takes place in the fallopian tube, after ovulation (14). Second, the progesterone concentration in blood plasma is crucial for ovulation itself. In most mammalian species, ovulation occurs when the progesterone level is basal (during luteolysis). In bitches, the granulosa and theca interna cells first luteinize, start producing progesterone, and ovulation is accompanied by high levels of progesterone (P4) in the blood (25). Therefore, the physiological uniqueness of bitches in the field of oocyte maturation and ovulation undoubtedly deserves an in-depth analysis. The knowledge of the molecular basis of this process will be crucial for further research and development of modern animal reproduction biotechniques (9). 
Various correlations and communication paths between the granulosa cells (GCs) surrounding the oocyte and the ovum, as well as between GCs and oviduct epithelial cells (OECs) (35), indicate that it is the intercellular interactions that might be responsible for the developmental competence of COCs. This in turn could result in the ability to fertilize and produce offspring. It is expected that it is the structural intercellular channels (such as aquaporins and gap junctions) that enable the transport of molecules and the transmission of signals which are crucial for mutual correlation and maturation. Up to now, factors regulating the resumption of meiotic division in oocytes after ovulation and systems of signal transduction in COCs have been poorly investigated. Accurate interactions between oocyte and cumulus oophorus have not been analyzed, while the study focused mainly on obtaining large numbers of mature oocytes in MII stage (9, $10,31)$. However, interaction between individual cells in COCs and OECs may be essential for full oocyte capacity to fertilize.

Recent years' research shows the important role played by aquaporins (AQPs) and gap junction connections' (GJCs) proteins - connexins (Cxs) in the maturation and acquisition of developmental competence in the organs of the mammalian reproductive system. Nevertheless, there are still few studies that describe the role of these proteins in relation to the canine reproductive system $(3-5,17-19,22,28,51,52,54,79)$. However, there are data that highlight the significant function of aquaporins and connexins in the maturation of oocytes in other domestic species such as pigs, mice, rats, cattle, sheep and even humans $(2,7,24,26$, $30-32,44,47,48,50,57,59,60,70,76)$. The specific course of ovulation in dogs therefore directs scientific research towards a molecular background that still leaves many uncertainties. Researchers must remain open-minded about the complexity of these processes.

\section{The structure, role and importance of aquaporins}

Aquaporins are significant structures involved in the water management of cells (11). Properly functioning water channels, called aquaporins, are responsible for the movement of water through the bilayer lipid membrane of the cell, which leads to the crucial ability of the cell to maintain proper intracellular pressure and water balance between the cell and the external environment $(27,38)$. The expression of the AQPs gene varies according to tissue type and species. It has been shown that one cell can express more than one AQPs isoform. In addition, these different isoforms can be located at the opposite ends of the cells: in the apical and basolateral membrane. Aquaporins exhibit a hydrophobic structure of integral membrane proteins and their weight ranges from 25 to $34 \mathrm{kDa}(27)$. Up to now, 13 AQPs (AQP0-AQP12) have been described. Some of them are selective water channels and belong here to $\mathrm{AQP} 0,1,2,4,5,6,8$. Whereas aquaglyceroporins are defined as those that transport glycerol, urea and other small water-soluble particles $\left(\mathrm{Cl}^{-}\right.$and $\left.\mathrm{Hg}^{2+}\right)$ with water. This group includes AQP3, 5, 7, 9 and 10. An additional group are superaquaporins (AQP11, 12) which have been recently discovered $(27,61)$. Most previous studies have focused on demonstrating the presence of AQP in tissues, knowledge of their structure and some physiological role.

During cancer studies on mice it was found that AQP1 is involved in endothelial cell migration and consequently in angiogenesis. Models of AQP knockout mice showed slower migration than the wild type (73). In knock-out mice, variable cerebrospinal fluid volume and intracranial pressure were also observed. Furthermore, overexpression AQPs was observed in different types of tumors, therefore a significant role of these proteins in cancer development was suggested (73).

It would also seem to be an important fact that different AQPs isoforms may be present in the same cell at opposite extremities. In the parotid gland cells of a domestic rat, expression of AQP3 in the basolateral membrane and AQP5 in the apical membrane of the cells was found.

Additionally, it was shown that AQP5 transport can be induced by $\mathrm{Ca}^{2+}$ ions, which takes place in intracellular lipid rafts (12). In cytosol, these rafts move in apical direction and are then incorporated into the cell membrane structure. The different location of these membrane proteins is not limited to the cell membrane alone. The presence of AQPs was also demonstrated in the nuclear membrane (12).

It was also shown that AQPs can be secreted into physiological fluids. The presence of AQP2 in urine was observed and this effect was explained by vasopressin action in kidneys collective ducts (13). As mentioned above, not only water can be transported through AQPs but also other particles. The concentration of glycerol and triglycerides increased in the blood plasma in mice lacking the gene AQP9 (53).

As the structure and function of AQPs was further developed, it has been proven that they not only act as water channels but often participate in other processes such as proliferation, cell migration or adhesion. Taking into account these mechanisms, it was examined whether they influence wound healing processes, especially in the eye cornea (36).

\section{Aquaporins in canines}

Studies in recent years have shown the presence of different AQPs in many tissues in canine animals. AQP1 and 2 have been shown to be present in the normal kidney of a dog, where the main function of these proteins is to transport water in the renal tubules (8). The study of AQP2 and its interaction with vasopressin in the kidneys is the basis for discovering the mechanisms of urine production and exploring new therapies. Madin-Darby canine kidney cells are used 
in cultures and are a model in studies of AQP2 inhibitors (16). AQP2 was even suggested to be a marker in dogs to differentiate between various states related to polyuric conditions by its detection in urine (75).

It is worth mentioning that a study was also performed to determine the role of AQP1 in the volume of erythrocytes (red blood cells, RBC) in dogs. AQP1 expression on the RBC membrane was analyzed using the Western Blot method, which did not show any significant differences between blood cell size and AQP1 expression level, proving that this water channel is not involved in controlling red blood cell volume in the dog (49).

An interesting area of research on AQPs in the recent past turns out to be the dog's eye, as increasingly often pathologies of the organ of vision are observed, which requires looking for the basis of the pathology and, consequently, causative treatment. AQP1, 3, 4, 5 were located in different parts of the dog's eye, including cornea (46), iris, ciliary body, retina and optic nerve. AQP5 was also found in the conjunctiva and nictitating membrane (29). The collected data indicate the role of AQPs in water management in a dog's eye. AQP1 has also been shown to play an important role in producing tears in healthy dogs (37). It is likewise suggested that deficiency of AQP5 in the lacrimal glands and nictitating membrane glands in dogs may be correlated with keratoconjunctivitis sicca (71).

The described proteins were also found in the brain and the entire nervous system in dogs. The expression of AQPs in cerebro-spinal fluid in hydrocephalus dogs was also increased compared to the control group (58).

One recent study analyzed the role of all 13 AQPs in intervertebral disc (IVD) degeneration in dogs and humans (65). Due to the fact that originally well hydrated IVDs lose turgor and function during degeneration, an attempt was made to determine the role of AQPs in this pathology. Significant expression of AQPs in IVD in both humans and dogs was demonstrated.

\section{Role of AQPs gene family in reproductive systems processes}

The first study showing the presence of AQPs in the reproductive tract was based on rats' uterus examination. The presence of AQP1 mRNA was then demonstrated (38). During the following years, researchers have demonstrated the presence of different AQPs in the reproductive system of different species of mammals, including mice (21) and humans (26). Subsequently, AQP1, 5 and 9 were described in several parts of the reproductive system in a domestic porcine animal (including the ovarian granulosa cells, oviduct and uterine) (62). AQP1 immunoreactivity was determined in the capillary endothelial cells of the oviduct, uterus and ovary. In turn, AQP5 was observed in granulosa cells and flattened cells of the primordial follicles in the ovary, uterine smooth muscle and the oviduct, whereas AQP9 immunoreactivity exhibited granulosa cells of developing follicles, oviduct epithelial cells and luminal and glandular uterus epithelial cells (62). Additionally, another work by this author proved that the expression of AQP1, 5 and 9 in the porcine endometrium and myometrium is different during the estrous cycle and early pregnancy (51). Variable expression values of analyzed genes in different periods of early pregnancy and during the estrous cycle suggest a significant influence of estrogen and progesterone on the expression of AQPs in porcine endometrium and myometrium. Another study (41) carried out on rats' ovarian follicles revealed that the rate of water transfer to follicular antral cavity consists mainly of transcellular transport and is mediated by AQP7, AQP8 and AQP9 of the ovarian granulosa cells. Additionally, the authors suggested a crucial role of aquaglyceroporins (AQP7 and 9), through which the simultaneous transport of other particles takes place. The transport function of the AQP3, 7 and 9 can also provide a path for androgenic substrates to estrogen production by GCs $(21,42)$.

The analysis and better understanding of the expression and function of AQPs in follicle cells and other cells of the reproductive system may lead to a better recognition of the processes that control the maturation of oocytes and consequently create their ability to fertilize and develop the embryo properly. It is worth emphasizing that studies on mouse oocytes, which suggest that increased expression of AQP3 improves water and glycerine permeability and in consecration may improve the survival of frozen oocytes (21). The above results may form the basis for research on the survival of canine embryos after freezing, which may lead to the development of modern assisted reproduction techniques for carnivorous animals. Nevertheless, studies by Meng et al. (42) have demonstrated that controlled ovarian stimulation causes a decrease in AQP3 expression, which may be one of the reasons for poor survival of frozen oocytes. Oocyte cryopreservation is still a challenge and methods of sperm and embryo protection are not sufficient for oocytes. The imperfections of these methods therefore constitute restrictions on the free movement of genetic material, advanced animal reproduction and maintenance of wild species.

Recently, the presence of AQP1, 5 and 9 has been demonstrated in the porcine granulosa cells (GCs), theca cells (TCs) (44) and oviductal epithelial cells (64) during the estrous cycle. The recent years' research on the expression of AQPs in porcine reproductive organs has also brought further valuable information on their potential role. The studies on GCs and TCs of porcine ovarian follicles showed that gonadotropins and growth hormone increase the expression of AQP1 in the examined cells, originating from medium and large vesicles. Furthermore, it was demonstrated that prolactin had a stimulating effect on AQP1 expression in the ovarian follicular cells. The authors suggest that AQP1 can also influence cell proliferation and migra- 
tion $(44,60,62-64)$. In addition, we recently analyzed the expression level of AQPs and Cxs genes in the pig's endometrium during primary in vitro culture (81). The results show significant changes in $\mathrm{Cx} 43$ expression and elevated AQP4, 7, 8 and 11 levels, which correlates with strong changes in epithelial cells during the estrous cycle.

\section{Aquaporins and the canine reproductive system}

Referring to available global literature, only a few studies have been conducted on the presence of AQP in the reproductive tract of bitches. The first study demonstrates the presence of AQP1, AQP2 and AQP5 in the uterus of bitches showing regular estrous cycles (3). This study shows that the estrous cycle did not affect the distribution and expression of AQP1. Nonetheless, the expression of AQP2 in glandular epithelium and luminal epithelium depended on the estrogenic environment. Additionally, the location of AQP5, which showed expression in the apical side of endometrial cell membrane depending on the increase in plasma concentration of $\mathrm{P} 4$, was presented. Therefore, taking into account the previously mentioned data, it can be assumed that there is a functional cooperation between different AQPs in water distribution in different stages of the estrous cycle.

The second publication on AQPs in the reproductive system in bitches describes the presence of these proteins in the placenta and foetal membranes at different stages of pregnancy. Aralla et al. (4) collected samples during natural delivery, caesarean sections or through ovario-hysterectomies of undesirable pregnancy. The presence of AQP1, 3, 5, 8 and -9 was assessed using immunohistochemical techniques. The volume and biochemical composition of amniotic fluid during pregnancy was also analyzed. The results showed distinct patterns of AQP1, 3, 5, 8 and -9 expression in maternal and extraembryonic tissues. The authors suggest that AQPs are important in mediating amniotic fluid during pregnancy (4).

Apparently, more research on aquaporins has been conducted on the male reproductive system in dogs. Studies were conducted where AQP1, 2, 7 (19) and 9 (18) were described in different regions of epididymis and vas deferens and AQP1 was found in male gametes (28). The next study on male dogs was performed in order to assess the cellular distribution of AQPs in normal and cryptorchid testicles (51). It is well known that the proper intercellular water flow during maturation of sperm in male gonads is extremely important. The immunohistochemical location of AQP7, AQP8 and AQP9 was demonstrated in both types of testes, although the cryptorchid testes were characterized by a lower amount of AQP7 and higher amount of AQP9 mRNA transcripts and protein. This experience indicates the role of AQPs in maintaining testicular cell volume. Additionally, the authors suggest that the different distribution of AQPs in cryptorchid testes in relation to normal ones reveals the possibility of early detection and prevention of neoplastic diseases (51). The presence of AQP1, 3, 4, 7, 8 and -9 in dogs has also been immunohistochemically demonstrated in gubernaculum testis tissues of fetuses during different stages of pregnancy (5). The authors suggest a significant contribution of AQPs to hydration and volume modification of gubernaculum testis in dogs.

Finally, AQP1 was also analyzed in the mammary gland in healthy bitches and in the case of mammary tumors. High expression was expected in the case of tumors, due to human literature data. However, no homologies were found, suggesting different expression profiles of aquaporins in different mammalian species (22).

\section{The structure, role and importance of connexins}

Gap junction connections (GJCs) are made up of connexins, integral membrane proteins, which form complexes - connexones (1). They have a structure consisting of 6 subunits, surrounding a channel of $1.5 \mathrm{~nm}$ diameter. A single connexon can connect to the connexon of an opposite cell and create gap junction channels (33). The flow of ions between the cells creates a difference in electrical potential. Due to the construction of gap junctions they can be divided into several classes. The combination of two connexons with one type of protein is called a homometrichomotopic junction. However, those formed from two connexones, but different kinds of proteins are called homometric-heterotypic junctions. Conversely, in the case of heterometric-homotypic junctions each connexon consists of two types of proteins. Thus, the greatest variety of proteins is characterized by heterometric-heterotopic junctions.

There are 21 genes defined in the mammalian connexins family, many of which may be expressed within the same cell (67). The group consists of 18 versatile connexins (Cx26, Cx29/31.3, Cx30, Cx30.2/31.9, Cx30.3, Cx31, Cx31.1, Cx32, Cx36, Cx37, Cx39/40.1, Cx40, Cx43, Cx45, Cx44/46, Cx47, Cx50, and $\mathrm{Cx} 57 / 62)$ and three species-specific proteins (Cx25 and $\mathrm{Cx} 58$ in primates, $\mathrm{Cx} 33$ in rodents) (15).

Different types of connexins are found in different types of body cells because intercellular communication is an extremely important element of cell life. It has been shown that Cxs not only form specific gap junction connections, but also through their structure have the ability to connect with other structural proteins, consequently influencing various cellular processes $(20,47,57,80)$. The existence of GJCs in various body tissues ensures the maintenance of homeostasis, intracellular metabolic cooperation and the transmission of important cellular signals (59).

\section{Connexins in canines}

Studies in recent years have shown the presence of different connexins in many canine tissues. Three 
gap junctional proteins have been identified in canine ventricular myocytes: connexin $43(\mathrm{Cx} 43)$, connexin $45(\mathrm{Cx} 45)$, and connexin $40(\mathrm{Cx} 40) . \mathrm{Cx} 43$ is the predominant gap junctional protein in the working myocardium while $\mathrm{Cx} 40$ is found at the highest levels in the conduction system. Cx45 has been detected in adult canine ventricular myocytes where it colocalizes with $\mathrm{Cx} 43$ and $\mathrm{Cx} 40$ (66). Western blot studies showed a decrease in the amount of $\mathrm{Cx} 43$ in both the left and right atrium of the boxer dogs diagnosed with arrhythmogenic right ventricular cardiomyopathy (ARVC). It was evaluated that a gap junction degradation and the electrical uncoupling in conjunction with histological changes may contribute to atrial arrhythmogenesis associated with ARVC (74).

A subject of the extensive proliferation and secretory differentiation of epithelium, which require tight regulation of hormonal and growth factor cues as well as epithelial-epithelial and epithelial-stromal interactions, and direct cell - cell communication through gap junctions are also mammary glands (67). In normal bitch mammary tissue, $\mathrm{Cx} 43$ is primarily expressed between myoepithelial cells whereas $\mathrm{Cx} 26$ is detected between secretory cells $(40,72)$. A comparative study showed that canine mammary tumor cells (CMT12, CMT27, and CF41.Mg) have lower gap junction activity compared to non-cancerous cells (CMEC). A distinct differential pattern of connexin 26 and connexin 43 between normal and cancerous mammary cells in dogs may possibly allow novel therapeutics to be developed (40).

It is noteworthy that in the intestinal tissues of dogs a group of connexins which are attributed to the participation of pacemakers and neurotransmitter processes has also been distinguished. Using some specific antibodies, it has determined the distribution of three types of connexins in the whole gastrointestinal tract $(\mathrm{Cx} 43, \mathrm{Cx} 45$, and $\mathrm{Cx} 40)(45,78)$. Connexin 40 (Cx40) was widely distributed in the circular muscle of the lower esophageal sphincter (LES), stomach, and ileum (78). Connexin 43 (Cx43) was present along the main division of the circular smooth muscle layer cell surface in the small intestine and the border layer between the circular muscle and the submucosa and in the portion of the circular muscle layer of the canine colon (interstitial cells of Cajal rich layer, ICC) $(39,43)$. Connexin $45(\mathrm{Cx} 45)$ was localized along the deep muscular plexus of the small intestine which may suggest that connexin 45-expressing cells are likely to act as a constituent conductive system by forming a cellular network operating via specific types of gap junctions (45). In addition, thanks to detection of the colocalization of $\mathrm{Cx} 43$ with $\mathrm{Cx} 40$ and/or $\mathrm{Cx} 45$ in the ICC networks it has been proved that gap junctions in canine intestines based on different connexin compositions may be heterotypic or heteromeric and have different conductance properties in different regions (78).
Connexins 43 and 46 were considered to have a significant impact on the development, differentiation and regulation of bone tissue, both normal and neoplastic (56). By relating of the proliferating cell nuclear antigen (PCNA), which enables the evaluation of cellular proliferation in the tumors to $\mathrm{Cx} 43$ and $\mathrm{Cx} 46$ levels, it has proven an inverse correlation in a case of GJCs' proteins (higher amounts of $\mathrm{Cx} 43$ were associated with fewer PCNA-positive cells). In this context the increase of the expression of specific bone tissue Cxs could be used as adjuvant in the treatment of canine osteosarcomas (56).

\section{Role of connexins gene family in reproductive systems processes}

The male reproductive tract is composed of several cell types interconnected through GJCs composed with several varying isotypes of Cxs, depending on the organ, the species and the developmental stages. An expression of exclusively $\mathrm{Cx} 43$ genes was found in testicular Leydig cells of various species. In Sertoli cells, the most important somatic cells in the seminiferous tubules due to their function as nurturing the germ cell lineage, several $\mathrm{Cx}$ isoforms of numerous species, like human, mouse, rat, pig, and dog were found (Cx26, Cx32, Cx33, Cx43). The knowledge on Cx expression in germ cell lineage is highly limited; however, $\mathrm{Cx} 43$ was detected in human and dog germ cells (32).

During the following years, researchers have demonstrated the presence of different Cxs in the reproductive system of different species of mammalian females. In the ovary of many species, including humans, mice, swine, bovine, ovine and canine $\mathrm{Cx} 37$ and $\mathrm{Cx} 43$ are the most abundantly expressed connexins $(7,23,48$, 70). The essential aspect in the process of acquiring developmental competence by oocyte is its proper communication with cumulus oophorus cells. The presence of specific gap junction connections (GJCs) has been demonstrated, with connexins being the most crucial proteins building them (6).

Many studies in recent years have shown significant expression of connexin $43(\mathrm{Cx} 43)$ during both oocyte (50) and granulosa cells $(30,31)$ in vitro primary culture. This protein (GJA1, gap junction associated protein, alpha 1 , also known as $\mathrm{Cx} 43$ ) turns out to be the main constituent in the connections between individual GCs populations: mural-mural and muralCCs (68). Through gap-junctions, direct exchange of substrates for both ions $\left(\mathrm{Na}^{+}, \mathrm{Ca}^{2+}\right)$, metabolites and secondary messengers up to $1.2 \mathrm{kDa}$ (e.g. ATP) is possible $(69,77)$. In recent years, many studies have been conducted on the role of Cxs in oocyte maturation, the acquisition of developmental competence by COCs, and consequently fertilization capacity. The results show that the lack of these proteins may lead to disorders of oocyte development processes, leading to their inability to fertilize $(2,24,76)$. 


\section{Connexins and the canine reproductive system}

In the available literature the authors have found only a few publications on the presence of Cxs in the reproductive tract of dogs. Most of them are related to the occurrence of the gap junctions in the canine testicular tissue. Recent studies reveal that GJCs, including a predominant connexin 43, between Leydig, Sertoli and between Sertoli and germ cells participate in the local regulation of spermatogenesis and it is crucial for its initiation and maintenance $(52,54)$.

Only two studies about the expression of Cxs in ovarian follicles in bitches during the estrous cycle were found. The gene expression of both connexins (connexin $43(\mathrm{Cx} 43)$ and connexin $37(\mathrm{Cx} 37)$ ) were observed in all stages of follicular development. However, the mRNA levels of both genes remained without changes at the final follicular growth, suggesting that, in contrast to other species, they may be involved in the prolonged meiotic arrest $(17,79)$.

In conclusion, therefore, by studying the available literature it can be stated that water channels and gap - junction connections undoubtedly play an important role in the regulation of the reproductive system function. Studies in pigs show a significant expression of AQPs proteins in the most important reproductive organs, and their close relationship with their function indicates their significant participation in cyclic changes in particular cell types. In turn, connexins are unquestionably the main building proteins of GJCs, thus providing key oocyte - cumulus cell relationships and ion and molecular exchange. The uniqueness of the estrous cycle in bitches raises even more questions and hypotheses about the molecular basis of their reproduction. In response to the still developing field of carnivorous animal reproduction, the key seems to be the necessity of further research, allowing for continued development of assisted reproductive techniques.

\section{References}

1. Aasen T., Leithe E., Graham S. V., Kameritsch P., Mayán M. D., Mesnil M., Pogoda K., Tabernero A.: Connexins in cancer: bridging the gap to the clinic. Oncogene 2019, 38, 4429-4451.

2. Ackert C. L., Gittens J. E., O'Brien M. J., Eppig J. J., Kidder G. M.: Intercellular communication via connexin43 gap junctions is required for ovarian folliculogenesis in the mouse. Dev. Biol. 2001, 233, 258-270.

3. Aralla M., Borromeo V., Groppetti D., Secchi C., Cremonesi F., Arrighi S.: A collaboration of aquaporins handles water transport in relation to the estrous cycle in the bitch uterus. Theriogenology 2009, 72, 310-321.

4. Aralla M., Mobasheri A., Groppetti D., Cremonesi F., Arrighi S.: Expression of aquaporin water channels in canine fetal adnexa in respect to the regulation of amniotic fluid production and absorption. Placenta 2012, 33, 502-510.

5. Arrighi S., Aralla M., Fracassetti P., Mobasheri A., Cremonesi F.: Aquaporin water channels in the canine gubernaculum testis. Acta Histochem. 2013, 115, 541-548

6. Beyer E. C., Berthoud V. M.: Gap junction gene and protein families: Connexins, innexins, and pannexins. Biochim. Biophys. acta Biomembr. 2018, 1860, 5-8.

7. Borowczyk E., Johnson M. L., Bilski J. J., Borowicz P., Redmer D. A., Reynolds L. P., Grazul-Bilska A. T.: Gap junctional connexin 37 is expressed in sheep ovaries. Endocrine 2006, 30, 223-230.

8. Brandt L. E., Bohn A. A., Charles J. B., Ehrhart E. J.: Localization of canine, feline, and mouse renal membrane proteins. Vet. Pathol. 2012, 49, 693-703.

9. Bukowska D., Kempisty B., Antosik P., Jackowska M., Woźna M., Lianeri M., Jaśkowski J. M.: Association between the number and quality of bitch COCs and selected donor factors. Med. Weter. 2010, 66, 480-483.
10. Bukowska D., Kempisty B., Antosik P., Jaśkowski J. M., Olechnowicz J.: Wybrane aspekty związane z dojrzewaniem oocytów, zapłodnieniem oraz rozwojem zarodkowym u psów (Selected aspects of canine oocytes maturation, fertilization and embryo development in dogs). Med. Weter. 2008, 64, 628-631.

11. Carbrey J. M., Agre P.: Discovery of the aquaporins and development of the field. Handb. Exp. Pharmacol. 2009, 3-28.

12. Cho G., Bragiel A. M., Wang D., Pieczonka T. D., Skowronski M. T., Shono M., Nielsen S., Ishikawa Y.: Activation of muscarinic receptors in rat parotid acinar cells induces AQP5 trafficking to nuclei and apical plasma membrane. Biochim. Biophys. Acta 2015, 1850, 784-793.

13. Chung S. H., Jun D. W., Kim K. T., Chae J. D., Park E. K., Son B. K., Kim S. H., Jo Y. J., Park Y. S.: Aquaporin-2 urinary excretion in cirrhosis: relationship to vasopressin and nitric oxide. Dig. Dis. Sci. 2010, 55, 1135-1141.

14. Concannon P. W.: Reproductive cycles of the domestic bitch. Anim. Reprod. Sci. 2011, 124, 200-210.

15. Cruciani V., Mikalsen S.-O.: The connexin gene family in mammals. Biol. Chem 2005, 386, 325-332.

16. Deen P. M., Rijss J. P., Mulders S. M., Errington R. J., van Baal J., van Os C. H. Aquaporin-2 transfection of Madin-Darby canine kidney cells reconstitutes vasopressin-regulated transcellular osmotic water transport. J. Am. Soc. Nephrol. 1997, 8, 1493-1501.

17. De los Reyes M., Palomino J., Espinoza R., Gallego C.: 116 Differential expression of connexin 43 and 37 mRNA transcripts during the estrous cycle in canines. Reprod. Fertil. Dev. 2019, 31, 184.

18. Domeniconi R. F., Orsi A. M., Justulin L. A., Beu C. C. L., Felisbino S. L. Aquaporin 9 (AQP9) localization in the adult dog testis excurrent ducts by immunohistochemistry. Anat. Rec. (Hoboken) 2007, 290, 1519-1525.

19. Domeniconi R. F., Orsi A. M., Justulin L. A., Leme Beu C. C., Felisbino S. L.: Immunolocalization of aquaporins 1, 2 and 7 in rete testis, efferent ducts, epididymis and vas deferens of adult dog. Cell Tissue Res. 2008, 332, 329-335.

20. Donfack N. J., Alves K. A., Alves B. G., Rocha R. M. P., Bruno J. B., Bertolini M., Dos Santos R. R., Domingues S. F. S., De Figueiredo J. R., Smitz J., Rodrigues A. P. R.: Stroma cell-derived factor 1 and connexins (37 and 43) are preserved after vitrification and in vitro culture of goat ovarian cortex. Theriogenology 2018, 116, 83-88

21. Edashige K., Sakamoto M., Kasai M.: Expression of mRNAs of the Aquaporin Family in Mouse Oocytes and Embryos. Cryobiology 2000, 40, 171-175.

22. Freeman A., Hetzel U., Cripps P.: Expression of the plasma membrane markers aquaporin 1 (AQP1), glucose transporter 1 (GLUT1) and Na, K-ATPase in canine mammary glands and mammary tumours. Vet. J. 2010, 185, 90-93.

23. Gershon E., Plaks V., Dekel N.: Gap junctions in the ovary: expression, localization and function. Mol. Cell Endocrinol. 2008, 282, 18-25.

24. Gittens J. E. I., Kidder G. M.: Differential contributions of connexin 37 and connexin 43 to oogenesis revealed in chimeric reaggregated mouse ovaries. J. Cell Sci. 2005, 118, 5071-5078.

25. Hollinshead F., Hanlon D.: Normal progesterone profiles during estrus in the bitch: A prospective analysis of 1420 estrous cycles. Theriogenology 2019, 125, 37-42.

26. Huang H.-F., He R.-H., Sun C.-C., Zhang Y., Meng Q.-X., Ma Y.-Y.: Function of aquaporins in female and male reproductive systems. Hum. Reprod. Update 2006, 12, 785-795.

27. Ishikawa Y., Cho G., Yuan Z., Skowronski M. T., Pan Y., Ishida H.: Water channels and zymogen granules in salivary glands. J. Pharmacol. Sci. 2006, 100, 495-512.

28. Ito J., Kawabe M., Ochiai H., Suzukamo C., Harada M., Mitsugi Y., Seita Y., Kashiwazaki N.: Expression and immunodetection of aquaporin 1 (AQP1) in canine spermatozoa. Cryobiology 2008, 57, 312-314

29. Karasawa K., Tanaka A., Jung K., Matsuda A., Okamoto N., Oida K., Ohmori K., Matsuda H.: Patterns of aquaporin expression in the canine eye. Vet. J. 2011, 190, 72-77

30. Kempisty B., Ziótkowska A., Ciesiótka S., Piotrowska H., Antosik P., Bukowska D., Nowicki M., Brüssow K. P., Zabel M.: Study on connexin gene and protein expression and cellular distribution in relation to real-time proliferation of porcine granulosa cells. J. Biol. Regul. Homeost. Agents 2014, 28, 625-635.

31. Kempisty B., Ziółkowska A., Piotrowska H., Ciesiótka S., AntosikP., Bukowska D., Zawierucha P., Woźna M., Jaśkowski J. M., Brüssow K. P., Nowicki M., Zabel M.: Short-term cultivation of porcine cumulus cells influences the cyclin-dependent kinase $4(\mathrm{Cdk} 4)$ and connexin $43(\mathrm{Cx} 43)$ protein expression-a real-time cell proliferation approach. J. Reprod. Dev. 2013, 59, 339-345.

32. Kibschull M., Gellhaus A., Carette D., Segretain D., Pointis G., Gilleron J.: Physiological roles of connexins and pannexins in reproductive organs. Cell Mol. Life Sci. 2015, 72, 2879-2898.

33. Kidder G. M., Mhawi A. A.: Gap junctions and ovarian folliculogenesis Reproduction 2002, 123, 613-620.

34. Kulus M., Kranc W., Sujka-Kordowska P., Mozdziak P., Jankowski M., Konwerska A., Kulus J., Bukowska D., Skowroński M., Piotrowska-Kempisty H., Nowicki M., Kempisty B., Antosik P.: The processes of cellular growth, aging, and programmed cell death are involved in lifespan of ovarian granulosa cells during short-term IVC - Study based on animal model. Theriogenology 2020 , $148,76-88$. 
35. Kulus M., Kulus J., Popis M., Borowiec B., Stefańska K., Celichowski P. Nawrocki M. J., Brüssow K. P., Kempisty B., Jeseta M., Antosik P., Bukowska D.: "Cell cycle" and 'cell death'- Related genes are differentially expressed during long-term in vitro real-time cultivation of porcine oviductal epithelial cells. Med. J. Cell Biol. 2019, 7, 90-99.

36. Kumari S. S., Varadaraj M., Menon A. G., Varadaraj K.: Aquaporin 5 promotes corneal wound healing. Exp. Eye Res. 2018, 172, 152-158.

37. Lamagna B., Ciaramella P., Lamagna F., Di Loria A., Brunetti A., Pelagalli A.: Aquaporin 1 (AQP1) Expression in Healthy Dog Tears. Animals 2020, 10, 820.

38. Li X. J., Yu H. M., Koide S. S.: Regulation of water channel gene (AQP CHIP) expression by estradiol and anordiol in rat uterus. Acta Pharm. Sin. 1997, 32, 586-592.

39. Li Z., Zhou Z., Daniel E. E.: Expression of Gap Junction Connexin 43 and Connexin 43 mRNA in Different Regional Tissues of Intestine in Dog. Am. J. Physiol. 1993, 265, 911-916.

40. Luu S., Bell C., Schneider S., Nguyen T. A.: Connexin 26 and Connexin 43 in Canine Mammary Carcinoma. Vet. Sci. 2019, 6, 101.

41. McConnell N. A., Yunus R. S., Gross S. A., Bost K. L., Clemens M. G., Hughes F. M.: Water Permeability of an Ovarian Antral Follicle Is Predominantly Transcellular and Mediated by Aquaporins. Endocrinology 2002, 143, $2905-$ -2912 .

42. Meng Q.-X., Gao H.-J., Xu C.-M., Dong M.-Y., Sheng X., Sheng J.-Z., Huang H.-F: Reduced Expression and Function of Aquaporin-3 in Mouse Metaphase-II Oocytes Induced by Controlled Ovarian Hyperstimulation were Associated with Subsequent Low Fertilization Rate. Cell Physiol. Biochem. 2008, 21, 123-128.

43. Mikkelsen H. B., Huizinga J. D., Thuneberg L., Rumessen J. J.: Immunohistochemical localization of a gap junction protein (connexin43) in the muscularis externa of murine, canine, and human intestine. Cell Tissue Res. 1993, 274, 249-256

44. Motkowska P., Tanski D., Eliszewski M., Skowronska A., Nielsen S., Skowronski M. T: : The expression profile of AQP1, AQP5 and AQP9 in granulosa and theca cells of porcine ovarian follicles during oestrous cycle and early pregnancy. J. Anim. Feed Sci. 2018, 27, 26-35.

45. Nakamura K., Kuraoka A., Kawabuchi M., Shibata Y.: Specific localization of gap junction protein, connexin45, in the deep muscular plexus of dog and rat small intestine. Cell Tissue Res. 1998, 292, 487-494.

46. Nautscher N., Bauer A., Steff M., Amselgruber W. M.: Comparative morphological evaluation of domestic animal cornea. Vet. Ophthalmol. 2016, 19, 297-304.

47. Nitta M., Yogo K., Ohashi M., Akiyama M., Kunitomo Y., Ogawa T., IshidaKitagawa N., Miyoshi J., Sato E., Takeya T.: Identification and Expression Analysis of connexin-45 and connexin-60 as Major Connexins in Porcine Oocytes. J. Anim. Sci. 2010, 88, 3269-3279.

48. Nuttinck F., Peynot N., Humblot P., Massip A., Dessy F., Fléchon J. E. Comparative Immunohistochemical Distribution of Connexin 37 and Connexin 43 Throughout Folliculogenesis in the Bovine Ovary. Mol. Reprod. Dev. $2000,57$.

49. Ochiai H., Onda K., Maruo T., Kanemaki N.: Aquaporin-1 expression in canine peripheral erythrocytes and its relation to cell volume. Exp. Anim. 2011, 60, 89-91.

50. Pandey A., Gupta N., Gupta S. C.: Improvement of in vitro oocyte maturation with lectin supplementation and expression analysis of Cx43, GDF-9, FGF-4 and Fibronectin mRNA transcripts in Buffalo (Bubalus bubalis). J. Assist. Reprod. Genet. 2009, 26, 365-371.

51. Pelagalli A., Squillacioti C., Ali'S., Liguori G., Mirabella N.: Cellular distribution of aquaporins in testes of normal and cryptorchid dogs: A preliminary study on dynamic roles. Anim. Reprod. Sci. 2019, 204, 22-30.

52. Pointis G., Segretain D.: Role of connexin-based gap junction channels in testis. Trends Endocrinol. Metab. 2005, 16, 300-306.

53. Rojek A. M., Skowronski M. T., Füchtbauer E.-M., Füchtbauer A. C., Fenton R. A., Agre P., Frøkiaer J., Nielsen S.: Defective glycerol metabolism in aquaporin 9 (AQP9) knockout mice. Proc. Natl. Acad. Sci. USA 2007, 104, 3609-3614.

54. Rüttinger C., Bergmann M., Fink L., Pesch S., Seitz K., Trautmann A., Steger K., Konrad L., Brehm R.: Expression of connexin 43 in normal canine testes and canine testicular tumors. Histochem. Cell Biol. 2008, 130, 537-548.

55. Rybska M., Knap S., Jankowski M., Jeseta M., Bukowska D., Antosik P., Nowicki M., Zabel M., Kempisty B., Jaśkowski J. M.: Cytoplasmic and nuclear maturation of oocytes in mammals - living in the shadow of cells developmental capability. Med. J. Cell Biol. 2018, 6, 13-17.

56. Sanches D. S., Pires C. G., Fukumasu H., Cogliati B., Matsuzaki P., Chaible L. M., Torres L. N., Ferrigno C. R. A., Dagli M. L. Z.: Expression of connexins in normal and neoplastic canine bone tissue. Vet. Pathol. 2009, 46, 846-459.

57. Santiquet $N$., Robert $C$., Richard F. J.: The dynamics of connexin expression, degradation and localisation are regulated by gonadotropins during the early stages of in vitro maturation of swine oocytes. PLoS One 2013, 8, 68456

58. Schmidt M. J., Rummel C., Hauer J., Kolecka M., Ondreka N., McClure V., Roth J.: Increased CSF aquaporin-4, and interleukin-6 levels in dogs with idiopathic communicating internal hydrocephalus and a decrease after ventriculo-peritoneal shunting. Fluids Barriers CNS 2016, 13, 12.
59. Shimada M., Maeda T., Terada T.: Dynamic changes of connexin-43, gap junctional protein, in outer layers of cumulus cells are regulated by PKC and PI 3-kinase during meiotic resumption in porcine oocytes. Biol. Reprod. 2001, $64,1255-1263$

60. Skowronska A., Mlotkowska P., Eliszewski M., Nielsen S., Skowronski M. T. Expression of aquaporin 1, 5 and 9 in the ovarian follicles of cycling and early pregnant pigs. Physiol. Res. 2015, 64, 237-245.

61. Skowronski M. T.: Distribution and quantitative changes in amounts of aquaporin 1,5 and 9 in the pig uterus during the estrous cycle and early pregnancy. Reprod. Biol. Endocrinol. 2010, 8, 109.

62. Skowronski M. T., Kwon T.-H., Nielsen S.: Immunolocalization of aquaporin 1 , 5 , and 9 in the female pig reproductive system. J. Histochem. Cytochem. 2009, 57, 61-67.

63. Skowronski M. T., Mlotkowska P., Tanski D., Lepiarczyk E., Oklinski M. K., Nielsen S., Skowronska A.: Pituitary Gonadotropins, Prolactin and Growth Hormone Differentially Regulate AQP1 Expression in the Porcine Ovarian Follicular Cells. Int. J. Mol. Sci. 2018, 19, 5

64. Skowronski M. T., Skowronska A., Nielsen S.: Fluctuation of aquaporin 1, 5 , and 9 expression in the pig oviduct during the estrous cycle and early pregnancy. J. Histochem. Cytochem. 2011, 59, 419-427.

65. Snuggs J. W., Day R. E., Bach F. C., Conner M. T., Bunning R. A. D., Tryfonidou M. A., Le Maitre C. L.: Aquaporin expression in the human and canine intervertebral disc during maturation and degeneration. JOR SPINE 2019, 2, 1049.

66. Steiner E., Ebihara L.: Functional characterization of canine connexin45. J. Membr. Biol. 1996, 150, 153-161.

67. Stewart M. K. G., Simek J., Laird D. W.: Insights into the role of connexins in mammary gland morphogenesis and function. Reproduction 2015, 149, 279-290.

68. Su Y.-Q., Sugiura K., Eppig J. J.: Mouse Oocyte Control of Granulosa Cell Development and Function: Paracrine Regulation of Cumulus Cell Metabolism. Semin. Reprod. Med. 2009, 27, 32.

69. Sugimura S., Kobayashi N., Okae H., Yamanouchi T., Matsuda H., Kojima T., Yajima A., Hashiyada Y., Kaneda M., Sato K., Imai K., Tanemura K., Arima T., Gilchrist R. B.: Transcriptomic signature of the follicular somatic compartment surrounding an oocyte with high developmental competence. Sci. Rep. 2017, 7, 6815 .

70. Teilmann S. C.: Differential expression and localisation of connexin-37 and connexin-43 in follicles of different stages in the 4-week-old mouse ovary. Mol. Cell Endocrinol. 2005, 234, 27-35.

71. Terakado K., Yogo T., Kohara Y., Soeta S., Nezu Y., Harada Y., Hara Y. Amasaki H., Tagawa M.: Marked depletion of the water-channel protein, AQP5, in the canine nictitating membrane glands might contribute to the development of KCS. Vet. Pathol. 2013, 50, 664-667.

72. Torres L. N., Matera J. M., Vasconcellos C. H., Avanzo J. L., Hernandez-Blazquez F. J., Dagli M. L. Z.: Expression of connexins 26 and 43 in canine hyperplastic and neoplastic mammary glands. Vet. Pathol. 2005, 42, 633-641.

73. Verkman A. S., Hara-Chikuma M., Papadopoulos M. C.: Aquaporins - new players in cancer biology. J. Mol. Med. (Berl) 2008, 86, 523-529.

74. Vila J., Pariaut R., Moïse N. S., Oxford E. M., Fox P. R., Reynolds C. A., Saelinger $C$.: Structural and molecular pathology of the atrium in boxer arrhythmogenic right ventricular cardiomyopathy. J. Vet. Cardiol. 2017, 19, 57-67.

75. Vonderen I. K. van, Wolfswinkel J., van den Ingh T. S. G. A. M., Mol J. A., Rijnberk A., Kooistra H. S.: Urinary aquaporin-2 excretion in dogs: a marker for collecting duct responsiveness to vasopressin. Domest. Anim. Endocrinol. 2004, 27, 141-153.

76. Vozzi C., Formenton A., Chanson A., Senn A., Sahli R., Shaw P., Nicod P., Germond M., Haefliger J.: Involvement of connexin 43 in meiotic maturation of bovine oocytes. Reproduction 2001, 122, 619-628.

77. Wang H.-X., Tong D., El-Gehani F., Tekpetey F. R., Kidder G. M.: Connexin expression and gap junctional coupling in human cumulus cells: contribution to embryo quality. J. Cell Mol. Med. 2009, 13, 972-984.

78. Wang Y. F., Daniel E. E.: Gap junctions in gastrointestinal muscle contain multiple connexins. Am. J. Physiol. Gastrointest. Liver Physiol. 2001, 281, 533-543.

79. Willingham-Rocky L. A., Golding M. C., Wright J. M., Kraemer D. C., Westhusin M. E., Burghardt R. C.: Cloning of GJA1 (connexin43) and its expression in canine ovarian follicles throughout the estrous cycle. Gene Expr. Patterns 2007 , 7, 66-71.

80. Winterhager E., Kidder G. M.: Gap junction connexins in female reproductive organs: implications for women's reproductive health. Hum. Reprod. Update 2015, 21, 340-352

81. Wojtanowicz-Markiewicz K., Kulus M., Knap S., Kocherova I., Jankowski M., Stefańska K., Jeseta M., Piotrowska-Kempisty H., Bukowska D., Zabel M., Mozdziak P., Nowicki M., Kempisty B., Antosik P.: Expression of Selected Connexin and Aquaporin Genes and Real-Time Proliferation of Porcine Endometrial Luminal Epithelial Cells in Primary Culture Model. Biomed. Res. Int. 2020, 7120375

Corresponding author: Magdalena Kulus, DVM, Department of Veterinary Surgery, Institute of Veterinary Medicine, Nicolaus Copernicus University in Toruń, 87-100 Toruń, 7 Gagarina St., Poland; e-mail: magdalena. kulus@umk.pl 